SHORT REPORT

\title{
The electrophysiological profile of hereditary motor and sensory neuropathy-Lom
}

\author{
B A Ishpekova, L G Christova, A S Alexandrov, P K Thomas
}

J Neurol Neurosurg Psychiatry 2005;76:875-878. doi: 10.1136/jnnp.2004.040030

\begin{abstract}
Objective: To make electrophysiological observations on a large kindred with hereditary motor and sensory neuropathyLom (HMSN-L) containing 27 affected individuals.

Clinical findings: Onset was in early childhood with gait difficulty related to progressive lower limb weakness. Upper limb weakness developed later. Bulbar involvement was present in one third of the patients, and deafness appeared during the second or third decades.

Electrophysiological findings: Electromyographic evidence of denervation was progressive, more severe distally, and greater in the legs, being total in distal lower limb muscles in most patients. Sensory action potentials were absent and motor nerve conduction was severely slowed. This included proximal upper limb (musculocutaneous and axillary), hypoglossal, and facial nerves. The severity of slowing increased during childhood. M waves, often multiple, were recorded in all affected individuals. The blink reflex showed an unusual three component response. The latencies of all three components were prolonged.

Conclusions: HMSN-L is shown to be a demyelinating neuropathy involving severe and early axonal loss. The progressive slowing of nerve conduction during childhood differs from the static reduction seen in type I HMSN.
\end{abstract}

$\mathrm{N}$ ine forms of demyelinating autosomal recessive hereditary motor and sensory neuropathies (HMSN) associated with defects in seven loci, and six genes have been identified, included within type 4 Charcot-MarieTooth disease (CMT4), namely CMT4A (GDAP1); CMT4B1 (MTMR2); CMT4B2 (MTMR13); CMT4C (5q23-q33); CMT4D HMSN-L (NDRG1), CMT4E (ERG2); CMT4F (PRX1), CCFDN (18q23-qter), and HMSNR ( $\log 23){ }^{1}$

There is considerable variation in the clinical and pathological features of autosomal recessive HMSN, and the electrophysiological findings enable individual varieties to be distinguished. HMSN-L is an autosomal recessive demyelinating disorder recognised in a gypsy family. ${ }^{2-8}$ It has been shown to be caused by a mutation in the n-myc downstream regulated gene 1 (NDRG 1). ${ }^{9}$ The disorder is characterised by onset in early childhood of a progressive neuropathy, later consistently associated with deafness. ${ }^{3}$ In this study we describe new electrophysiological findings observed on needle electromyography in kindred with HMSN-L-that is, the presence of A waves and a three component blink reflex. There were also changes in hypoglossal nerve conduction velocity and in ulnar and peroneal motor nerve conduction velocities (MCV) on dynamic testing.

\section{METHODS}

Clinical information was obtained from 47 members of a Bulgarian gypsy family, of whom 27 were affected ( 11 male and 16 female; ages 7 to 56 years). The clinical features conformed to those already described for HMSN-L and the diagnosis was confirmed by genetic linkage to chromosome $8 \mathrm{q} 24$.

The investigation had the approval of the ethics committee of the Medical University, Sofia.

Needle electromyography of distal and proximal upper limb muscles (abductor digiti minimi, abductor pollicis brevis, biceps brachii, deltoid), distal lower limb muscles (extensor digitorum brevis, abductor hallucis, tibialis anterior), facial muscles (frontalis, orbicularis oris), and the lingual muscles was carried out using standard concentric needle electrodes.

Motor nerve conduction velocities in the median, ulnar, tibial, and peroneal nerves and late responses ( $\mathrm{F}$ and $\mathrm{A}$ waves) were examined by conventional clinical methods.

The evoked compound muscle action potential (CMAP) was recorded with conventional surface electrodes and its parameters (amplitude, area, duration, and latency) were measured. Changes in CMAP parameters after proximal compared with distal stimulation in each nerve segment were calculated as [proximal CMAP/distal CMAP] $\times 100 \%$. Temporal dispersion was defined as greater than $15 \%$ increase in the duration of the negative peak for the responses of the median and ulnar nerves, and as a greater than $25 \%$ increase for the peroneal nerve.

Conduction time in the axillary and musculocutaneous nerves was investigated using routine methods, and CMAP was recorded with concentric needle electrodes. ${ }^{10}$ The conduction time of the facial nerve was evaluated by the latency of CMAP recorded from orbicularis oris muscle with standard surface electrodes with a small leading off area. ${ }^{11}$ Conduction in hypoglossal nerve was investigated by the method of Ishpekova and Baykushev. ${ }^{12}$ CMAP was recorded from standard concentric needle electrodes. Repeated nerve conduction studies in the seven youngest patients over three consecutive years were carried out to examine the evolution of the disorder.

The electrically elicited orbicularis oculi reflex was studied by the method of Dengler et al. ${ }^{13}$ The evoked responses were recorded from pairs of electrodes with small leading off areas. Soleus $\mathrm{H}$ reflexes were evaluated using a standard technique.

Sensory conduction was examined antidromically in the median, ulnar, and sural nerves using surface stimulating and recording electrodes.

\section{RESULTS}

Total denervation with complete electrical silence in the small foot muscles was present in 26 patients (96\%). Denervation potentials of the small hand muscles were detected in 19 patients $(71 \%)$, and of muscles below the knees in $15(54 \%)$.

Abbreviations: CMAP, compound muscle action potential; HMSN-L, hereditary motor and sensory neuropathy-Lom; MCV, motor nerve conduction velocity 
A

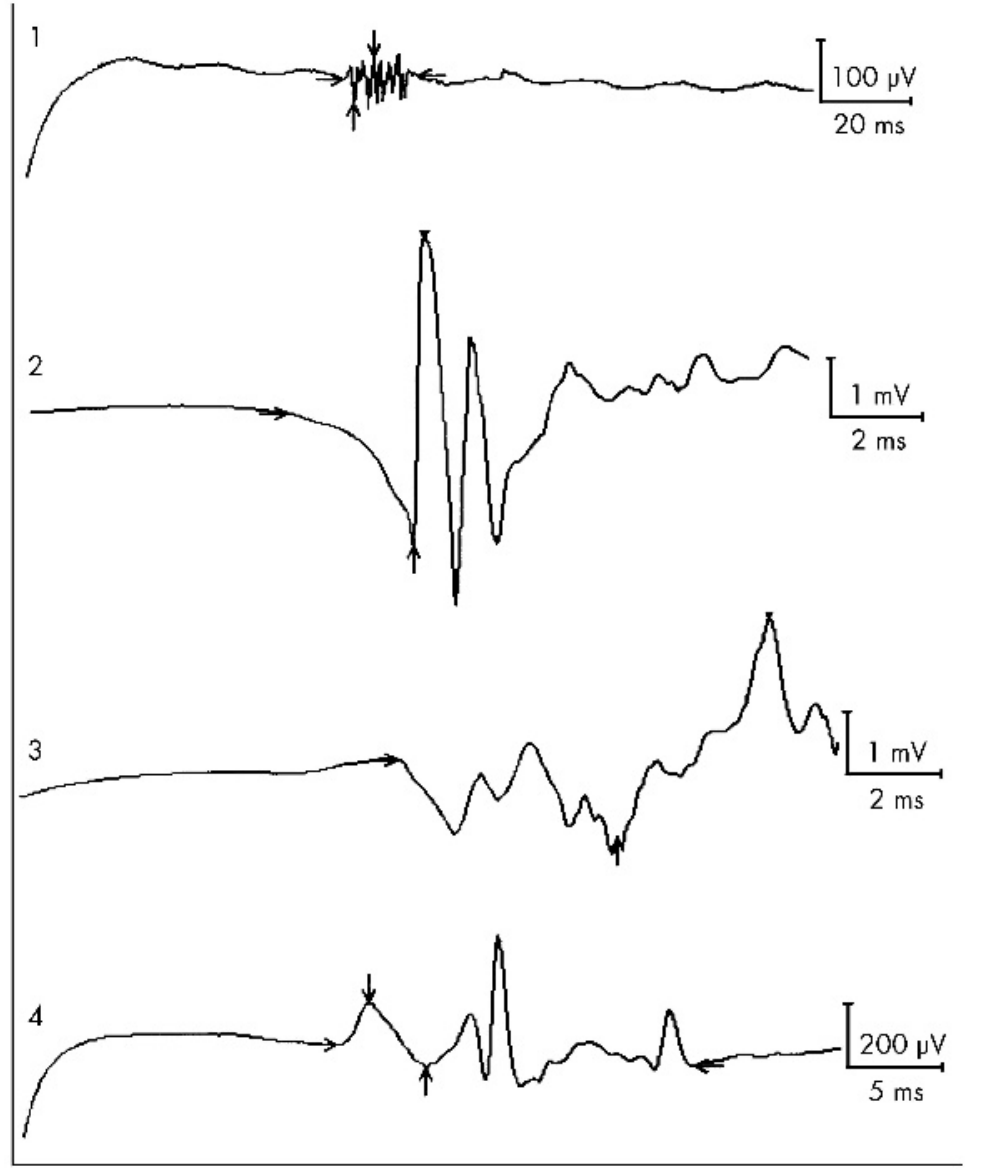

B
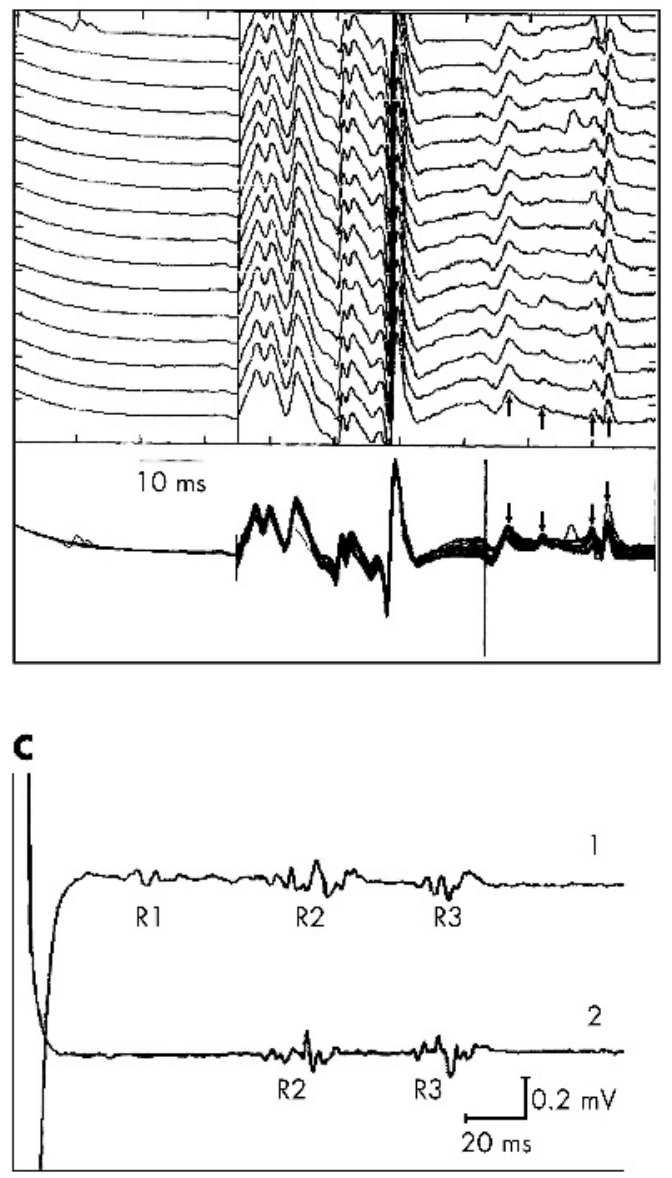

Figure 1 (A) Multiple evoked $M$ responses recorded from different muscles. Trace 1: $\mathrm{m}$ abductor digiti $\mathrm{V}$; trace 2: $\mathrm{m}$ deltoideous; trace 3: $\mathrm{m}$ biceps brachii; trace 4: $\mathrm{m}$ orbicularis oris. (B) $M$ responses and multiple $A$ waves (noted with arrows), recorded from abductor digiti $\bigvee$ muscle in a patient with HMSN-L. (C) The electrically evoked three response blink reflex recorded from $\mathrm{m}$ orbicularis oculi in a patient with HMSN-L. Trace 1: three responses $\left(R_{1}, R_{2}\right.$, and $\left.R_{3}\right)$ on the side of stimulation; trace 2: on the contralateral side $\left(R_{2}\right.$ and $\left.R_{3}\right)$. HMSN-L, hereditary motor and sensory neuropathy-Lom.

Evidence of chronic partial denervation with reinervation (reduced motor unit pattern with motor unit potentials of increased amplitude and duration) was found in $13(50 \%), 12$ $(46 \%)$, and $5(17 \%)$ individuals, respectively, in the distal and proximal muscles of the upper limbs and in the proximal muscles of the lower limbs.

The distal to proximal changes in CMAP amplitude and duration were significantly greater than in unaffected subjects, but determination was difficult because of the presence of polyphasic responses (fig 1A). In 15 affected members the reduction in proximal CMAP amplitude of the

Table 1 Motor nerve conduction velocity, distal latency, and proximal latency of the unar and peroneal nerves

\begin{tabular}{llll}
\hline & MCV $(\mathrm{m} / \mathrm{s})$ & DL $(\mathrm{ms})$ & PL $(\mathrm{ms})$ \\
\hline Ulnar nerve & & & \\
Patients $(\mathrm{n}=27)$ & $9.6(1.1)$ & $20.4(2.9)$ & $53.4(7.0)$ \\
Unaffected members $(\mathrm{n}=20)$ & $55.2(1.4)$ & $3.4(0.1)$ & $7.9(2.3)$ \\
& & & \\
& & & \\
Peroneal nerve & $17.4(2.2)$ & $9.5(1.3)$ & $22.8(3.3)$ \\
Patients $(\mathrm{n}=7)$ & & &
\end{tabular}

Values are mean (SD).

$\mathrm{DL}$, distal latency; MCV, motor nerve conduction velocity; PL, proximal latency. ulnar nerve exceeded 50\%, and excessive temporal dispersion was seen in nine patients (33\%).

In all patients, MCV and distal and proximal latencies for the ulnar nerve were five times lower than in healthy family members. In $79 \%$ of patients the changes to the distal and proximal latencies of the ulnar nerve were homogeneous (Spearman $r=0.89$ ). Because of total denervation of the peroneal nerves in 20 patients, MCV could only be measured in the seven youngest and was three times lower than in unaffected family members (table 1 ). Repeated MCV studies in these patients over three consecutive years showed that both the proximal and distal latencies were twice as long on the last occasion as on the first investigation.

A marked reduction in conduction time was observed for the axillary nerve $(\mathrm{n}=17$; mean value, $14.5(0.8) \mathrm{ms})$ and for the musculocutaneous nerve ( $\mathrm{n}=27$; mean 23.2 (1.3) ms). In healthy subjects the latency for both nerves is $<4 \mathrm{~ms}$. Conduction time was also prolonged in the facial $(\mathrm{n}=27)$ and hypoglossal nerves $(n=26)$, at $16.7(0.5) \mathrm{ms}$ and 12.7 (1.3) ms, respectively. An upper limit of normal of $3.3 \mathrm{~ms}$ was accepted for the hypoglossal nerve.

In the 19 subjects from whom a CMAP was obtained in the abductor digiti minimi muscle, $\mathrm{F}$ waves were recorded in only three. On stimulation at the elbow, latencies of more than $50 \mathrm{~ms}$ were obtained (normal $<23 \mathrm{~ms}$ ). Multiple A waves were recorded from the upper limbs and the facial muscles in the remaining 16 cases. They were of lower amplitude and 
shorter duration and of constant shape and latency compared with the $\mathrm{F}$ waves (fig $\mathrm{lB}$ ).

Median, ulnar, and sural sensory action potentials were unobtainable in any of the HMSN-L patients, as were $\mathrm{H}$ reflexes.

The blink reflex on the side ipsilateral to the stimulation consisted of three components $\left(\mathrm{R}_{1}, \mathrm{R}_{2}\right.$, and $\mathrm{R}_{3}$ ) (fig $\mathrm{lC}$, trace 1) instead of the usual two which are recordable in normal subjects. On the contralateral side the latter two components $\left(R_{2}\right.$ and $R_{3}$ ) were present (fig $1 C$, trace 2 ). The responses were distinct in all patients and their mean latencies were prolonged in comparison with those of healthy subjects. The latencies for $R_{1}, R_{2}$, and $R_{3}$ responses were 31.1 (1.7), 70.0 (2.3), and 129.0 (2.9) $\mathrm{ms}$, respectively. Corresponding values for healthy subjects are $R_{1}=10-12 \mathrm{~ms}$ and $R_{2}=30-$ $40 \mathrm{~ms}^{14}{ }^{15}$

\section{DISCUSSION}

The progressive distally accentuated limb weakness in patients affected the lower limbs to a greater extent than the upper. A uniform slowing of conduction in all the nerves investigated was indicated by the significant correlation $(r=0.89)$ between the various nerves, including the more proximal musculocutaneous, axillary, facial, and hypoglossal nerves.

There was a severe and progressive reduction in MCV, this being evident from an early age, with muscle denervation. The progressive nature of the demyelinating process is supported by the fact that both the proximal and the distal latencies were twice as long on the most recent examination as they were at the time of the first MCV studies in the seven youngest patients three years before. Furthermore, the MCV of the ulnar nerve in these young patients had a range of 12.9 to $22.9 \mathrm{~m} / \mathrm{s}$, compared with 2.0 to $13.3 \mathrm{~m} / \mathrm{s}$ in the older patients. Because of total denervation in the older patients, the peroneal MCV could not be measured. This contrasts with CMTIA, in which the reduction in MCV remains stable despite continuing denervation, ${ }^{16}$ indicating a different relation between demyelination and axonal loss in our patients.

Facial weakness was only slight and inconstant; nevertheless, slowing of conduction was severe. Along with an increase in conduction time, there was a significant reduction in CMAP amplitude of the orbicularis oris. Atrophy of the tongue was observed in one third of the patients and the conduction time of the hypoglossus nerve was increased by a factor of 4 in comparison with healthy subjects.

Although more than half the patients showed more than $50 \%$ reduction in proximal as opposed to distal CMAP amplitude, this was difficult to interpret in view of temporal dispersion and a polyphasic $\mathrm{M}$ wave response.

The A waves observed in all nerves during conventional testing of F waves were as described by Tomasulo, ${ }^{17}$ and as found in different types of neuropathy. ${ }^{18-20}$ Because of the homogeneous disturbance of the nerves in HMSN-L, the presence of A waves confirms the view that they do not originate from ephaptic transmission. ${ }^{21}$

An unusual three component blink reflex was observed in the HMSN-L patients. The R3 component appears to be distinct temporally from R2. It could only be evoked by strong electrical pulses and had a latency about $50 \mathrm{~ms}$ longer than R2 in healthy subjects. ${ }^{15} 22$ R1 latency was increased 2.5 times over normal values. The latencies of the R2 and R3 components were prolonged 1.61- and 1.75-fold, respectively. The medium thick myelinated A-beta fibres are mainly responsible for the $\mathrm{R} 1$ component, whereas $\mathrm{R} 2$ is mediated by the nocioceptive thin myelinated A-delta fibres. ${ }^{23}{ }^{24}$ The cutaneous A-beta and nocioceptive A-delta fibres contribute to the generation of the very late component R3. ${ }^{25}$ Identical changes of R2 and R3 components in HMSN-L patients support the conclusion that the reflex arc for R2 and R3 uses the same brain stem pathways. ${ }^{15}$

In conclusion, HMSN-L has a characteristic electrophysiological profile. Denervation in the limbs is progressive and of early onset. MCV is severely and homogeneously reduced, and conduction slowing increases during childhood. Evoked CMAP are markedly dispersed and A waves are frequent. The early onset, the severity of the clinical involvement, and the reduction in $\mathrm{MCV}$, make it possible to categorise HMSN-L as an example of Dejerine-Sottas disease (DSD) but the value of retaining DSD as a diagnostic label is now questionable. It clearly does not identify a separate entity but merely describes a severe demyelinating neuropathy of early onset. The disability in HMSN-L is the result of progressive axonal loss, the explanation for which must await the elucidation of the normal function of the n-myc downstream regulated gene in the control of myelination and Schwann cell/axon relations.

\section{Authors' affiliations}

B A Ishpekova, Department of Medical Neurology, Medical University, Sofia, Bulgaria

L G Christova, A S Alexandrov, Institute of Biophysics, Bulgarian Academy of Sciences, Sofia

P K Thomas, University Department of Clinical Neurology, Institute of Neurology, London, UK

Competing interests: none declared

Correspondence to: Dr L G Christova, Institute of Biophysics, Bulgarian Academy of Sciences, Acad G Bontchev Str Bl 21, 1113 Sofia, Bulgaria; lilly@bio.bas.bg

Received 11 March 2004

In revised form 30 August 2004

Accepted 17 September 2004

\section{REFERENCES}

1 Kuhlenbaumer G, Young P, Hunermund G, Ringelstein B, Stogbauer F. Clinical features and molecular genetics of hereditary peripheral neuropathies. J Neurol 2002;249:1629-50.

2 Kalaydjieva L, Hallmayer J, Chandler D, Savov A, Nikolova A, Angelicheva D, et al. Gene mapping in Gypsies identifies a novel demyelinating neuropathy on chromosome 8q24. Nat Genet 1996;14:214-17.

3 Kalaydjieva L, Nikolova A, Turnev I, Petrova J, Hristova A, Ishpekova B, et al. Hereditary motor and sensory neuropathy-Lom, a novel demyelinating neuropathy associated with deafness in gypsies. Clinical, electrophysiological and nerve biopsy findings. Brain 1998;121:399-408.

4 Merlini L, Villanova M, Sabatelli P, Trogu A, Malandrini A, Yanakiev P, et al. Hereditary motor and sensory neuropathy Lom type in an Italian Gypsy family. Neuromuscul Disord 1998;8:182-5.

5 Colomer J, Iturriaga C, Kalaydjieva L, Angelicheva D, King RH, Thomas PK. Hereditary motor and sensory neuropathy-Lom (HMSNL) in a Spanish family: clinical, electrophysiological, pathological and genetic studies. Neuromuscul Disord 2000;10:578-83.

6 Butinar D, Zidar J, Leonardis L, Popovic M, Kalaydjieva L, Angelicheva D, et al. Hereditary auditory, vestibular, motor, and sensory neuropathy in a Slovenian Roma (Gypsy) kindred. Ann Neurol 1999;46:36-44.

7 Leonardis L, Zidar J, Popovic M, Timmerman V, Lofgren A, Van Broeckhoven $C$, et al. Hereditary motor and sensory neuropathy associated with auditory neuropathy in a Gypsy family. Pflugers Arch 2000;439(3 suppl):R208-10.

8 Baethmann M, Gohlich-Ratmann G, Schroder JM, Kalaydjieva L, Voit T. HMSNL in a 13-year-old Bulgarian girl. Neuromuscul Disord 1998;8:90-4.

9 Kalaydjieva L, Gresham D, Gooding R, Heather L, Baas F, de Jonge R, et al. $\mathrm{N}$-myc downstream-regulated gene 1 is mutated in hereditary motor and sensory neuropathy-Lom. Am J Hum Genet 2000;67:47-58.

10 Gassel MM. A test of nerve conduction to muscles of the shoulder girdle as an aid in the diagnosis of proximal neurogenic and muscular disease. J Neurol Neurosurg Psychiatry 1964;27:200-5.

11 Cohen HL, Brumlik J. Manual of electroneuromyography. New York: Harper and Row, 1968.

12 Ishpekova B, Baykushev S. A method of n. hypoglossus conductivity measurement. Folia Medica 1982;24:39-43.

13 Dengler R, Kossev A, Gippner C, Struppler A. Quantitative analysis of blink reflexes in patients with hemiplegic disorders. Electroencephalogr Clin Neurophysiol 1982;53:513-24. 
14 Kossev A Dengler R, Struppler A. Quantitative assessment of the blink reflex in normals physiological side-to-side differences and frequency-dependence. Electromyogr Clin Neurophysiol 1983;23:501-11.

15 Ellrich J, Hopf HC. The R3 component of the blink reflex: normative data and application in spinal lesions. Electroencephalogr Clin Neurophysiol 1996;101:349-54.

16 Thomas PK. Overview of Charcot-Marie-Tooth disease type 1A. Ann NY Acad Sci 1999; 14: 1-5.

17 Tomasulo RA. Aberrant conduction in human peripheral nerve: ephaptic transmission. Neurology 1982;32:712-19.

18 Bischoff C, Stalberg E, Falck B, Puksa L. Significance of A-waves recorded in routine motor nerve conduction studies. Electroencephalogr Clin Neurophysiol 1996;101:528-33.

19 Kostadinova SA. Peripheral late wave study in patients with discogenic radiculopathies. Electromyogr Clin Neurophysiol 1999;39:145-8.
20 Christova LG, Alexandrov AS, Ishpekova BA. Peripheral late waves in patients with hereditary motor sensory neuropathy. Electromyogr Clin Neurophysiol 1999;39:345-8.

21 Alexandrov AS, Christova LG, Ishpekova BA. A-waves in patients with novel hereditary motor and sensory neuropathy Lom. Acta Physiol Pharmacol Bulg $2001 \cdot 26 \cdot 55-8$

22 Rossi B, Risaliti R, Rossi A. The R3 component of the blink reflex in man: a reflex response induced by activation of high threshold cutaneous afferents. Electroencephalogr Clin Neurophysiol 1989:73:334-40.

23 Ellrich J, Bromm B, Hopf HC. Pain-evoked blink reflex. Muscle Nerve 1997; 20:265-70.

24 Esteban A. A neurophysiological approach to brainstem reflexes. Blink reflex. Neurophysiol Clin 1999;29:7-38.

25 Ellrich J, Katsarava Z, Przywara S, Kaube H. Is the R3 component of the human blink reflex nociceptive in origin? Pain 2001;91:389-95.

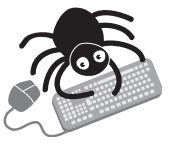

Please visit the Journal of Neurology, Neurosurgery, and Psychiatry website [www. innp.com] for a link to the full text of this article.

\section{Atypical antipsychotic drugs and risk of ischaemic stroke: population based retrospective cohort study}

Sudeep S Gill, Paula A Rochon, Nathan Herrmann, Philip E Lee, Kathy Sykora, Nadia Gunraj, Sharon-Lise T Normand, Jerry H Gurwitz, Connie Marras, Walter P Wodchis, Muhammad Mamdani

Objective: To compare the incidence of admissions to hospital for stroke among older adults with dementia receiving atypical or typical antipsychotics.

Design: Population based retrospective cohort study.

Setting: Ontario, Canada.

Patients: 32710 older adults ( $\geqslant 65$ years) with dementia (17 845 dispensed an atypical antipsychotic and 14865 dispensed a typical antipsychotic).

Main outcome measures: Admission to hospital with the most responsible diagnosis (single most important condition responsible for the patient's admission) of ischaemic stroke. Observation of patients until they were either admitted to hospital with ischaemic stroke, stopped taking antipsychotics, died, or the study ended.

Results: After adjustment for potential confounders, participants receiving atypical antipsychotics showed no significant increase in risk of ischaemic stroke compared with those receiving typical antipsychotics (adjusted hazard ratio 1.01, 95\% confidence interval 0.81 to 1.26 ). This finding was consistent in a series of subgroup analyses, including ones of individual atypical antipsychotic drugs (risperidone, olanzapine, and quetiapine) and selected subpopulations of the main cohorts.

Conclusion: Older adults with dementia who take atypical antipsychotics have a similar risk of ischaemic stroke to those taking typical antipsychotics.

\ BMJ 2005;330:445-448 